\title{
Testosterone and Dehydroepiandrosterone Treatment in Ageing Men: Are We All Set?
}

\author{
Andreas Walther ${ }^{1,2,3}$, , Julian Seuffert ${ }^{1}$ \\ ${ }^{1}$ Department of Biological Psychology, TU Dresden, Dresden, Germany, ${ }^{2}$ Department of Clinical Psychology and Psychotherapy, University \\ of Zurich, Zurich, Switzerland, ${ }^{3}$ Task Force on Men's Mental Health of the World Federation of the Societies of Biological Psychiatry (WFSBP)
}

\begin{abstract}
Although demographic statistics show that populations around the world are rapidly ageing, this rising life expectancy is accompanied by an increase in the number of people living with age-related chronic conditions, such as frailty, cognitive decline, depression, or sexual dysfunction. In men, a progressive decline in androgens occurs with increasing age, and low androgen levels are associated with age-related chronic conditions. However, androgen administration studies are inconclusive, showing differing results according to the androgen used (testosterone [T], dehydroepiandrosterone [DHEA]), the group of men examined (younger vs. older; eugonadal vs. hypogonadal) and the conditions studied (frailty, cognitive decline, depression, sexual dysfunction). In this review, the current state for the use of T and DHEA therapy in men for the age-related conditions is examined. Due to the progressive age-related decline in androgens leading to a higher rate of older men having low androgen levels, the effects of androgen treatment in elderly males will be of particular interest in this review. Doseresponse relationships, the role of potential moderators, and the androgen treatment-related risk for adverse events will be discussed. Studies have suggested that T treatment - more so than DHEA treatment - may be an effective therapy against agerelated chronic conditions in men with low T levels; especially older men. Such conditions include frailty, depression, or sexual dysfunction. However, $\mathrm{T}$ treatment does not emerge as an effective therapy against cognitive decline. Nevertheless, more high-quality, randomised controlled trials using $\mathrm{T}$ treatment for age-related chronic conditions are necessary if further conclusions are to be made.
\end{abstract}

Keywords: Aging; Dehydroepiandrosterone; Testosterone; Men; Healthy aging; Morbidity

This is an Open Access article distributed under the terms of the Creative Commons Attribution Non-Commercial License (http://creativecommons.org/licenses/by-nc/4.0) which permits unrestricted non-commercial use, distribution, and reproduction in any medium, provided the original work is properly cited.

\section{INTRODUCTION}

Demographic statistics show that populations around the world are rapidly ageing, but unfortunately this rising life expectancy is accompanied by an increase in the number of people suffering from chronic conditions, such as frailty, cognitive decline, depression, or sexual dysfunction [1,2]. Multi-morbidity amongst the elderly and the steadily increasing number of older individuals are considered to have contributed to a tremendous rise in health care costs, and it is not likely that this trend will come to an end in the foreseeable future [3,4]. Therefore, a healthy ageing process with fewer diseases and more independence of patients is one of the most crucial health care goals of our time. Furthermore, targeting biological ageing processes has

Received: Jan 10, 2019 Revised: Apr 24, 2019 Accepted: May 13, 2019 Published online Jun 4, 2019

Correspondence to: Andreas Walther (iD) https://orcid.org/0000-0003-4516-1783

Department of Biological Psychology, TU Dresden, Zellescher Weg 19, Dresden, 01069, Germany.

E-mail: andreas.walther@tu-dresden.de 
great potential to prevent, or at least delay, the onset and progression of multiple chronic diseases [5]. Over the last 30 years, research on a healthy ageing in men has increasingly focused on an age-related decline in androgens.

In men, a continuous decline in circulating androgen levels (e.g., testosterone [T] and dehydroepiandrosterone [DHEA]) occurs with increasing age [6,7]. Around the ages 35 to 40 years, the attrition of T-producing Leydig cells in the testes as well as cells in the zona reticularis of the adrenals responsible for DHEA production is already progressing [8,9]. An annual reduction in circulating $\mathrm{T}$ levels of approximately $1 \%$ to $3 \%$ and in DHEA of up to $4 \%$ has been reported [6,7,10]. Importantly, a decline in androgen levels is not a temporary phenomenon. Reports have shown progressive impairment of testicular/adrenal androgen function up until the 9th decade of life [11]. Men with lower T levels exhibit a worse state of general health [6,10], while a greater decline in circulating levels of androgen over five years has been associated with an increase in allcause and cause-specific mortality in older men [12]. Table 1 [10,13-16] shows selected adverse effects of low $\mathrm{T}$ and low DHEA levels and illustrates the versatility of negative consequences that arise from androgen deficiency.

Furthermore, numerous studies have indicated that

Table 1. Adverse effects of low testosterone (hypogonadism) and low DHEA levels

\begin{tabular}{lll}
\hline \multicolumn{1}{c}{ Variable } & \multicolumn{1}{c}{ Affected tissues/ } & \multicolumn{1}{c}{ Symptoms } \\
\hline Testosterone [13] & Bones & Osteoporosis \\
& Muscles & Atrophy \\
& Fat tissue & Increase \\
& Metabolism & Insulin resistance \\
& Mood & Depressed \\
& Cognition & Lower spatial \\
& & perception \\
& Libido, erection & Loss \\
& Penis, prostate and & Scaling down/ \\
& testes & atrophy \\
DHEA [10,14-16] & Sexual function & Decline \\
& General health & Decline \\
& Mood & Depressed \\
& Cognition & Memory degradation \\
& Cardiovascular system & Coronary \\
& & arteriosclerosis \\
\hline
\end{tabular}

DHEA: dehydroepiandrosterone. lower levels of $\mathrm{T}$ may be a risk factor for frailty [17,18], cognitive decline [19,20], depression [21,22], and sexual dysfunction $[23,24]$ in ageing men. However, the literature is inconsistent and there is also evidence that could not confirm any associations between $\mathrm{T}$ levels and the latter conditions [25,26]. A similar pattern emerges for circulating DHEA levels and frailty [27,28], cognitive decline [29,30], depression [31,32], and sexual dysfunction $[14,33]$. Again, there are several studies, which did not observe any association between DHEA levels and age-related chronic conditions [21,22]. A high function in mobility, cognition, mood, and sexuality remain highly important quality of life considerations in men until late life and a decrease in one of these areas significantly decreases overall life quality [25].

Although the findings for the endogenous hormone concentrations with regard to age-related chronic conditions are inconclusive, much effort has been undertaken to investigate the potential beneficial effect of androgen administration on these conditions. T prescriptions, but not DHEA prescriptions, significantly increased in the last decade and when proved as effective and safe, androgen treatment may become a geroprotective intervention in men, reducing, or at best preventing, specific age-related chronic complaints.

In the following, we will describe the current state of the two most applied androgen treatments ( $\mathrm{T}$ and DHEA treatment) in males for the age-related chronic conditions of frailty, cognitive decline, depression, and sexual dysfunction. The examination of literature on supplementation studies in older men will be of particular focus in this review. Finally, recent insights considering the influence of potential moderators as well as the safety of androgen treatment will be discussed. Although, we will focus on the dimensions of frailty, cognitive decline, depression, and sexual dysfunction, $\mathrm{T}$ treatment was previously also reported to have beneficial effects on lower urinary tract symptoms in ageing men. Therefore, it is important to keep in mind that the subsequently discussed sections are only a selection of potential dimensions of androgen treatment application.

\section{SEARCH STRATEGY}

The search strategy for this narrative review was based on the previously performed systematic searches of eight recent systematic searches in the field of $\mathrm{T}$ 
and DHEA treatment in men. Elliott et al [34] investigated broad effects of $\mathrm{T}$ treatment in hypogonadal men for the health dimensions quality of life, depression, libido, erectile function, activities of daily living and adverse events, while Isidori et al [35] and Boloña et al [36] specifically took the effect of $\mathrm{T}$ treatment on erectile dysfunction and sexual satisfaction into account. Walther et al [37] exclusively focused on randomized controlled trials (RCTs) using $\mathrm{T}$ treatment for depressive symptoms in men. Corona et al [38-40] examined DHEA treatment in elderly men for different health dimensions and also $\mathrm{T}$ treatment for sexual function, body composition, and adverse events. Grimley Evans et al [41] examined the effects of DHEA on cognitive dimensions in elderly. Based on these systematic searches, the most relevant administration studies to be included and highlighted in this narrative review were identified.

\section{TESTOSTERONE TREATMENT}

$\mathrm{T}$ treatment has recently been receiving a lot of attention for its potential beneficial effects, but it is only recommended for men who show symptoms of $\mathrm{T}$ deficiency and who repeatedly have low serum $\mathrm{T}$ concentrations [42]. In the following, evidence from $\mathrm{T}$ therapy studies on the age-related conditions frailty, cognitive impairment, depressive mood, and sexual dysfunction will be summarized. For a more concise overview, please consider Table 2 .

\section{Body composition}

Lifetime risk of fractures at the age of 50 is as high as $20 \%$ for men [43], and this risk increases exponen- tially for those over the age of 70 [44]. The prevalence of age-related sarcopenia - a clinical condition defined as below-threshold muscle mass - is reported to lie at $53.1 \%$ for moderate sarcopenia and $11.2 \%$ for severe sarcopenia in men over the age of 60 [45]. A 3-year T treatment study investigated 14 hypogonadal men (serum $\mathrm{T}$ levels $<250 \mathrm{ng} / \mathrm{dL}$ ) with a mean age of 51 years (range, 22-78 years) using physiologic $\mathrm{T}$ doses to reestablish normal $\mathrm{T}$ levels within the first three months of treatment. Bone mineral density and increased fatfree mass reached their maximum values by 24 months after treatment onset, with among others an increased density of the lumbar spine for about $7.6 \%$. Apart from that, also prostate volume, self-reported sense of energy and sexual function increased significantly [46]. Although these effects were in line with other studies examining 359 symptomatic hypogonadal men aged between 50 and 80 years [47], an inconclusive picture for the potential beneficial effect of $\mathrm{T}$ supplementation on body composition and frailty in older men was dominating for the past time since $\mathrm{T}$ treatment studies for example including 67 older men with low T levels aged 65 to 87 years showed only beneficial effects for body mass [48-50]. This is especially due to inconsistent results showing in 108 older men with low or age-normal but comparably low pretreatment $\mathrm{T}$ levels no positive effects on bone mineral density, while improved body composition was consistently replicated [50]. Recent studies in large samples using $\mathrm{T}$ supplementation in older men were able to clarify the association: $\mathrm{T}$ supplementation causes a significant decrease of body fat as well as an increase of lean body mass $(n=237)$ [51] and improves bone mineral density and bone strength in both the spine and the hip and thereby reducing

Table 2. Effects of testosterone treatment in different domains

\begin{tabular}{lll}
\hline \multicolumn{1}{c}{ Domain } & \multicolumn{1}{c}{ Beneficial/Adverse effects } & References \\
\hline Body composition & - Increase of bone mineral density and lean mass in hypogonadal men \\
& - Decrease of body fat, increase of bone mineral density and bone strength and therefore \\
& reduction of frailty in older men \\
- Small RCT found beneficial effects in several memory dimensions & [46-53] \\
- Replication failed in more representative RCTs & [55-62] \\
Mood and depressive & - Improvements in several depression severity measures in depressed and dysthymic patients \\
disorders & - In older men evidence is inconsistent \\
& - Inconsistent effects in treatment-resistant depressed men or HIV infected depressed men \\
- Identification of a dose-response relationship between testosterone and depressive symptoms & [37,64-71] \\
Sexual functioning & - Improvements in intercourse satisfaction, sexual desire and orgasm in men of all age categories
\end{tabular}

$\mathrm{RCT}$ : randomized controlled trial, HIV: human immunodeficiency virus. 
the risk of frailty and falls $(n=211)$ [52]. A recent metaanalysis examining the effect of $\mathrm{T}$ supplementation and body composition including 32 observational studies comprising of 4,513 patients confirmed an overall beneficial effect of $\mathrm{T}$ on body composition by reducing body fat, waist circumference and insulin resistance and improving the lipid profile, blood pressure and lean body mass [53].

\section{Cognition}

An increased cognitive decline with advanced ageing has been well-described, leading to high rates of dementia worldwide [54]. T supplementation, due to its neuroprotective effects, has been further suggested as a potential preventative measure against the onset of Alzheimer's disease or other forms of dementia. Although smaller RCTs administering T over 6 weeks in a sample of 32 men suffering from mild cognitive impairment or Alzheimer's disease revealed promising effects showing improvements in memory dimensions, others showed no beneficial effects examining $\mathrm{T}$ administration over 24 weeks in a sample of 16 Alzheimer cases compared to 22 controls [55,56]. In 22 men exhibiting low $\mathrm{T}$ levels and suffering from mild cognitive impairment no beneficial effects on cognition were identified except for an improvement in verbal memory [57], while in 25 healthy older men aged between 50 and 80 years a 6 -week $\mathrm{T}$ treatment caused significant improvements in spatial and verbal memory [58]. However, such effects were often not replicated by others indicating overall a nil-effect of $\mathrm{T}$ treatment on cognition [59-61]. Large RCTs including the T Trials sample of 788 older men with low T levels examining $\mathrm{T}$ supplementation in older men over a period of one year subsequently failed to provide further evidence of a beneficial effect with respect to cognitive functioning in the context of verbal episodic memory, cognitive and perceptual speed and visuospatial performance [51,62].

\section{Mood and depressive disorders}

Due to the enormous disease burden worldwide and the increasing rates of depressive disorders until the age of 65 years [63], the potential mood alleviating effect of $\mathrm{T}$ in men has been extensively investigated. For a RCT including 74 patients with a mean age of 39 years being human immunodeficiency virus (HIV) positive and showing low $\mathrm{T}$ levels, beneficial effects of a 6-week $\mathrm{T}$ supplementation on depressive symptom- atology were reported [64]. In 19 men aged between 30 and 65 years diagnosed with major depressive disorders and low serum T levels, an 8-week supplementation led to significant improvements in self-report measures of depression as well as in the Clinical Global Impression Scale [65]. Similar results for the same outcome measures have also been reported for 23 dysthymic men after a 6-week T treatment [66]. However, other reports examining $90 \mathrm{HIV}$ positive and depressed men using an 8-week T treatment [67] or in 26 treatment-resistant depressed men undergoing 6 weeks of $T$ treatment did not provide evidence for an improvement in depressive symptoms [68]. Considering only older men, a study investigating 120 men aged 60 to 74 years or the $\mathrm{T}$ Trials including 464 older men with low $\mathrm{T}$ levels have indicated a beneficial effect of $\mathrm{T}$ on $\operatorname{mood}[69,70]$. But there's also contradicting evidence showing after treatment cessation the control group to exhibit significantly better mood than the $\mathrm{T}$ supplementation group [71]. However, a recent meta-analysis of 27 RCTs on T administration including a total of 1,890 male subjects confirms the favorable effects in terms of effectiveness and efficacy ( $50 \%$ symptom reduction) of the treatment with respect to depressive symptoms [37]. Walther et al [37] further identified a dose-response relationship with higher dosed $\mathrm{T}$ regimes to show a larger reduction in symptoms. The consistent beneficial effects found for relatively high doses ( $>500 \mathrm{mg} / \mathrm{wk})$ suggest that $\mathrm{T}$ administration may be a potential additional therapy to current antidepressants. Nevertheless, neither clinical practice guidelines on $\mathrm{T}$ therapy in hypogonadal men [42] nor depression treatment guidelines [72] currently recommend $\mathrm{T}$ supplementation as an additional treatment in major depressive disorders in men.

\section{Sexual functioning}

With respect to sexual dysfunction, including reduced libido and erectile dysfunction, which are present in up to $77.5 \%$ of men over 75 years old [73], the results of most $\mathrm{T}$ treatment studies report beneficial effects. Though, there are studies which do not support $\mathrm{T}$ supplementation in older men with sexual dysfunction and low $\mathrm{T}$ levels for example examining 79 men aged 45 to 70 years undergoing a 16 -week T or DHEA treatment [74] or when examining 88 men with sexual dysfunction and type 2 diabetes undergoing 40 weeks of $\mathrm{T}$ treatment no relation between sexual symptoms and $\mathrm{T}$ levels was identified [75]. The majority of stud- 
ies, however, report a beneficial effect of T supplementation in multiple areas of sexual function, like intercourse satisfaction, sexual desire and orgasm [76-78]. In the sample of the $\mathrm{T}$ Trials comprising of 470 older men for the examination of the effect of $T$ on sexual symptoms, a moderate benefit with respect to sexual function was reported after the 1-year treatment period [70], while subsequent analyses revealed that $\mathrm{T}$ supplementation in older men with low serum $\mathrm{T}$ levels significantly improves sexual desire and activity and that these improvements were associated with higher increases in T and estradiol [79]. The beneficial effect of $\mathrm{T}$ supplementation on sexual function in men was also confirmed by two independent meta-analytic investigations (e.g., one including $14 \mathrm{RCT}$ of hypogonadal men comprising 3,167 patients) $[34,80]$. While both reports underline that publication bias needs to be considered, a relatively robust positive effect of $\mathrm{T}$ on erectile function, libido and quality of life was confirmed.

\section{DEHYDROEPIANDROSTERONE TREATMENT}

In contrast to T, which is increasingly being investigated and prescribed for its positive effects, DHEA supplementation in men was intensively investigated around two decades ago with regard to various health dimensions. In the following, the empirical evidence on effects of DHEA treatment with regard to different health-related dimensions is going to be presented and finally summarized in Table 3.

\section{Body composition}

An influential DHEA supplementation study including 133 men aged between 60 and 79 years published in the year 2000 did not reveal any beneficial effects on body composition or bone mineral density in older men after the 1-year treatment period [81]. Another influential study from the same year running for a 2-year period investigating 87 elderly men with low androgen levels however identified a slight yet significant increase of bone mineral density in only the femoral neck in men but also no effects on body composition or quality of life [82]. Furthermore, other studies undergoing a 1-year RCT treatment period comprising of study samples of 57 men (aged 65 to 75 years) or comprising of 9 men (aged 50 to 65 years) identified a reduction of fat mass in older men with DHEA supplementation $[83,84]$. This was further confirmed by a thorough meta-analysis on DHEA supplementation in older men including 25 placebo controlled trials comprising of 1,353 elderly men with a mean follow-up of 36 weeks [39]. Apart from the effect on fat mass, the analysis however failed to confirm any association of DHEA with bone health, metabolism or quality of life.

\section{Cognition}

With regard to the improvement of cognitive functioning in men, DHEA supplementation studies generally show poor results [85-88]. Wolf et al [85] report for a 2-week physiological DHEA administration in 25 healthy elderly men with a mean age of 69 years no beneficial effects on any cognitive dimension tested. Furthermore, 37 and 38 DHEA-treated women and men with an age range of 50 to 81 years were shown to recall less items from a visual memory test after a psychosocial stress test [86]. A 1-year DHEA RCT further revealed no beneficial effect on cognitive performance in 110 men aged 55 to 85 years [88]. Though, there have been reports of beneficial effects identifying significantly improved episodic memory performances in combination with altered event-related potentials following a 7-day DHEA treatment in 24 healthy young men [89]. However, a systematic review on RCTs of

Table 3. Effects of dehydroepiandrosterone treatment in different domains

\begin{tabular}{lll}
\hline \multicolumn{1}{c}{ Domain } & \multicolumn{1}{c}{ Beneficial/Adverse effects } & References \\
\hline Body composition & - Inconsistent evidence with regard to bone mineral density, bone health and metabolism & [39,81-84] \\
Cognition & - Reduction of fat mass in older men \\
& - Improvement of episodic memory in one study \\
Mood and depressive & - Some studies suggest mood enhancing effects \\
disorders & - Insufficient evidence to suggest beneficial effects \\
Sexual functioning & - Some studies report positive effects, other no effects \\
& - Insufficient evidence to suggest beneficial effects \\
\hline
\end{tabular}


DHEA supplementation on cognitive functioning in non-demented middle-aged and older men also concluded that there is no evidence for a beneficial effect especially since the existing evidence is little and severely inconsistent [41].

\section{Mood and depressive disorders}

While influential studies on DHEA supplementation report a beneficial effect on mood in comparison to placebo [90-92], other reports have produced contradictory results that suggest no improvement of mood due to treatment [85,88]. An 8-week DHEA treatment in 145 (122 men and 23 women) patients with HIV and subsyndromal depression or dysthymia led to a significant reduction of depressive symptoms compared to placebo [90]. Furthermore, in 23 men and 23 women aged between 45 and 65 years suffering form depressive disorders underwent a 6-week DHEA treatment leading to a signficant reduction in the treatment group compared to placebo indicating DHEA treatment as efficacious (23 individuals achieved $50 \%$ or greater symptom reduction in the DHEA group compared to 13 in the placebo group) [91]. These findings were in line with a previous report showing in 22 patients (12 men and 10 woman) with affective disorders (20 unipolar depression and 2 bipolar type 2 in the depressed phase) receiving 6-week DHEA treatment an efficacious response to treatment with 5 responders $(50 \%$ or greater treatment reduction) of the 11 patients treated with DHEA compared to 0 of the placebo group [92]. However, the previously mentioned study by Wolf et al [85] administering in a 2-week DHEA protocol in 40 healthy elderly individuals did not identify any benefits with regard to mood. Another RCT applying a 1-year DHEA treatment did also not reveal mood alleviating effects of DHEA in 110 men aged 55 to 85 years [88]. Additionally, there has been a recent yet somewhat questionable meta-analysis which included RCTs on DHEA supplementation suggesting beneficial effects of DHEA in depression [93]. However, based on these inconsistencies and the general shortage of empirical evidence, DHEA is not being considered as a potential antidepressant treatment in men.

\section{Sexual functioning}

With regard to sexual function in males and a potential beneficial effect by DHEA supplementation, findings are mixed, with some studies reporting positive ef- fects on sexual function for males [81,94,95] and others reporting no effects for males at all [74,96]. DHEA supplementation in 133 men aged between 60 and 79 years was not associated with beneficial effects on several libido parameters after the 1-year treatment period, while women aged 70 years or older showed significant improvement in libido due to DHEA treatment [81]. Another study applying a 30-week protocol of DHEA supplementation for 85 men with erectile dysfunction and comorbid different organic disorders achieved significant amelioration of erectile dysfunction in men with no additional organic disorders as well as for men with comorbid hypertension, but not with comorbid diabetes and neurological conditions [94]. However, a study examining 21 men and 27 women with hypoactive sexual desire in a 6-week DHEA RCT revealed no positive effects of DHEA on libido measures for men, but for women a positive effect of DHEA treatment on libido emerged [96]. It is further important to mention, that in the DHEA group men were significantly younger than in the placebo group potentially obscuring the true effect of DHEA since older men with sexual dysfunction show lower DHEA levels compared to younger men with sexual dysfunction [97]. The placebo controlled trial by Morales and colleagues examining 79 men with sexual dysfunction aged 45 to 70 years undergoing a 16-week T or DHEA treatment did also not identify any beneficial effects of DHEA treatment on symptoms of sexual dysfunction [74]. A meta-analysis examining 25 placebo controlled trials comprising of 1,353 elderly men with a mean follow-up of 36 weeks concluded that there is not sufficient evidence for a beneficial effect of DHEA on sexual function in men suggesting an association with negative age-related features such as hypertension or depression, which are both positively related to sexual dysfunction in males [39].

\section{COMPARABILITY OF DIFFERENT FORMULATIONS OF TESTOSTERONE AND DEHYDROEPIANDROSTERONE TREATMENTS}

There is generally no evidence for major discrepancies in different ways of $\mathrm{T}$ treatment [34]. However, the various forms of application offer certain advantages and disadvantages that need to be considered for the respective context. Bhasin et al [42] have summarized 
an extensive palette of formulations, showing that for example transdermal patches are easy to apply yet may cause skin irritation and aren't concentrated enough for severely deficient men, while transdermal gels provide flexible dosing but may quickly be transferred to a partner by direct skin contact. Oral formulations are easily applicable, often preferred by hypogonadal patients, but suffer from potential hepatic toxicity, while intramuscular injections on the other side are long lasting (usually applied for a period between two weeks up to three months), while dynamic dosing is difficult and assistance by a health professional is required [42].

In respect to DHEA, there are also various possibilities of applying the treatment. A common formulation is a transdermal gel ( $50 \mathrm{mg} / \mathrm{d})$, as it is quickly absorbed and metabolized and causes generally elevated steroid levels including T levels due to DHEAs' precursor function for many steroids [26]. Oral administration of 50 $\mathrm{mg} / \mathrm{d}$ shows similarly quick results in respect to serum DHEA or its sulfate levels. However to affect serum T levels higher dosages $(150 \mathrm{mg} / \mathrm{d})$ seem necessary [98]. There is an essential lack of studies evaluating the tolerance of different pharmacological formulations of DHEA, but generally no differences in adverse effects between the arrangements are reported [82].

\section{DISCUSSION}

\section{Summary}

For $\mathrm{T}$ treatment, beneficial effects emerged in terms of reducing frailty, depressive symptoms, and sexual dysfunction. These effects have also been reported for samples consisting exclusively of older men. There don't seem to be any cognitive improvements associated with $\mathrm{T}$ treatment for both non-demented younger men and non-demented or demented older men. DHEA treatment is not associated with a general improvement in frailty but shows modest effects in reducing fat mass in older men. No general effects emerge with regard to cognitive decline or for the reduction of depressive or sexual symptoms.

\section{General considerations associated with testosterone treatment}

Based on the reviewed literature, T, but not DHEA, emerges as a potential anti-ageing medication for frailty, mood and sexuality; thus the associated peculiarities and risks need to be examined. An important consid- eration is the comparability of different $\mathrm{T}$ treatments with four main variables: (i) administration (intra muscular, oral, or transdermal), (ii) dose (ranging from $0.05 \mathrm{~g} / \mathrm{d}$ to $1 \mathrm{~g} / \mathrm{d}$ ), (iii) frequency of application (ranging from daily to every 12 weeks), (iv) treatment duration (ranging from 3 weeks to 36 months). Elliot and colleagues conducted a network meta-analysis on $\mathrm{T}$ treatment studies in hypogonadal men, including several different $\mathrm{T}$ treatments [34]. For quality of life showing an overall effect of standardized mean difference (SMD) of -0.26 (95\% confidence interval [CI], -0.41 to $-0.11 ; n=2,834)$ the authors report of 14 different treatments, intramuscular $\mathrm{T}$ undecanoate (TU; 1,000 mg/12 wk) with an SMD of -0.48 (95\% CI, -0.84 to -0.10$)$ and oral TU $(160 \mathrm{mg} / \mathrm{d})$ with an SMD of -0.68 (95\% CI, -1.32 to -0.02$)$ to achieve significantly better results. For depressive symptomatology and erectile function, there was no significant difference for any of the nine individual $\mathrm{T}$ treatment approaches with an overall beneficial effect of SMD -0.23 for depressive symptomatology and SMD 0.25 for erectile function, suggesting all treatment approaches to achieve comparable results. In our recently conducted meta-analysis on T RCTs for depressive symptomatology in males showing a beneficial effect with a Hedge's $g=0.21$, we identified dose as a significant moderator, with higher dosed regimes achieving larger effects (e.g., $g$ for $0.1 \mathrm{~g} / \mathrm{wk}=0.166,0.3$ $\mathrm{g} / \mathrm{wk}=0.312,1 \mathrm{~g} / \mathrm{wk}=0.823$ ) [37]. Neither the method of administration nor the duration of treatment was further identified as a significant moderator.

\section{Treatment safety}

Reports on the potential detrimental effects of $\mathrm{T}$ treatment, such as increasing the risk of cardiovascular events [99,100] or prostate cancer [101], have caused long-lasting debates and heightened the sense of caution in the field, culminating in safety alerts issued by the United States Food and Drug Administration (FDA) in 2015 [102]. While the FDA upholds its safety alert for T products, the Pharmacovigilance Risk Assessment Committee (PRAC) of the European Medicines Agency clearly states that there is no consistent evidence of an increased risk of heart problems when using T medicine [103]. Recently, an expert consensus and extensive meta-analysis also concluded that evidence fails to support claims of increased risk of cardiovascular events or prostate cancer resulting from $\mathrm{T}$ treatment [34,40,101]. However, based on practice guide- 
lines and statements of the Endocrine Society, both FDA and PRAC have stated that approved T products should only be used in hypogonadal men in conjunction with an associated medical condition, such as testicular failure or genetic problems. They also stated that the restoration of $\mathrm{T}$ levels in otherwise healthy older men is not an authorized condition for use of such $\mathrm{T}$ products [42]. Yet, studies have shown that there is no $\mathrm{T}$ concentration threshold that reliably distinguishes between responders and non-responders to $\mathrm{T}$ treatment, suggesting that both hypogonadal and men currently identified as eugonadal with lower $\mathrm{T}$ levels may benefit from T treatment [101]. Finally, it is important to keep in mind that rare adverse events such as cardiovascular events or prostate cancer are difficult to investigate in RCTs. It is therefore highly necessary to investigate $\mathrm{T}$ treatment in prospective studies for a long-term period in order to be able to completely rebut any potential adverse consequences [70].

\section{Interference with endogenous steroid levels}

The last and often overlooked point to consider is the influence of T supplementation on endogenous $\mathrm{T}$ secretion. Since there is no clear threshold for T supplementation, it must be made clear to men with only slightly lowered $\mathrm{T}$ levels that this supplementation influences endogenous T production. Exogenous T administration triggers negative feedback processes in the hypothalamus-pituitary-gonadal axis which will eventually diminish the natural endogenous $\mathrm{T}$ production even more. Therefore, the decline in endogenous $\mathrm{T}$ may be further intensified by the use of $\mathrm{T}$ products. As long as we are not able to disprove this as a potential health threat, $\mathrm{T}$ products should only be used in men with $\mathrm{T}$ levels below a clinically relevant threshold, which does not need to correspond to the hypogonadism threshold. Thus, as indicated by leading researchers in the field [70], though available data shows insufficient evidence to support an increased risk for adverse events with $\mathrm{T}$ treatment, much larger trials of a much longer duration are needed in order to determine the risk of $\mathrm{T}$ treatment on male health. It may also only be possible to evaluate this after $\mathrm{T}$ treatment has been made accessible to larger parts of the male population (e.g., older men with steady declining $\mathrm{T}$ levels showing significantly reduced but not sub-threshold $\mathrm{T}$ levels) and after large post-marketing surveillance studies have become available.

\section{CONCLUSIONS}

Responding to the initial question of whether we are all set for $\mathrm{T}$ treatment (DHEA treatment as outlined above does not hold great promise), the answer is "No". More data is needed, which may only become available by conducting even larger RCTs than the recently conducted $\mathrm{T}$ Trials, or by making $\mathrm{T}$ treatment available for more, well-defined groups of men, who have low risk for adverse events and are probable to significantly benefit from $\mathrm{T}$ treatment. It is important that $\mathrm{T}$ is understood as a therapeutic and not a life style product, so that only men with clinically relevant symptomatology in areas, such as sexual function, frailty, or mood are going to be considered for $\mathrm{T}$ treatment at all. Furthermore, future studies will have to apply parallel designs to identify optimal dosage regimens. The question of which baseline $\mathrm{T}$ level a men must fall below to be considered for therapy, or which age groups respond most positively to $\mathrm{T}$ treatment, remains to be investigated further.

\section{Practice points}

1) Although good effects were shown for T treatment for body composition, depression, and erectile function, it is important to apply the recommendations by the Endocrine Society for T or DHEA treatment and to treat only men who are eligible due to hypogonadism and the corresponding symptom criteria for $\mathrm{T}$ deficiency.

2) Age is an important criterion for androgen treatment, since dynamic reference ranges must be taken into account due to the age-related decrease of androgens.

3) Although different types of androgen and especially $\mathrm{T}$ treatments are available, the different treatments seem to have similar effects.

4) With regard to certain symptom dimensions, doseresponse relations could be found. These associations must be further substantiated before a notion of "higher doses produce better effects" can be established.

5) Although there is accumulating evidence of a lack of association between $\mathrm{T}$ treatment and adverse events, much larger studies with longer follow-up need to prove this. 


\section{Research agenda points}

1) Since there is still much uncertainty about age limits for treatment indication or treatmentresponse in different age groups, further studies need to provide more clarity in this regard for androgen treatment.

2) Future RCTs of T treatment must use different dosage regimens in parallel to identify the ideal dosages for the appropriate health condition.

3) More high quality androgen treatment studies with clearly identified end points in clearly specified populations are needed to produce larger samples subsequently available for meta-analytic approaches.

4) Larger and longer-lasting studies are needed to identify the rare adverse drug reactions.

5) There is currently a predominance of studies with androgen treatment in men, although this could also be used in certain groups of women. More research on androgen treatment is needed in women.

\section{Conflicts of Interest}

Dr. Walther and M.Sc. Seuffert are exclusively employed by the TU Dresden as research assistants and have no potential conflicts of interest to disclose.

\section{Author Contribution}

Conceptualization: AW. Investigation: AW, JS. Methodology: AW, JS. Writing-original draft: AW. Writing-review \& editing: JS.

\section{REFERENCES}

1. Beard JR, Officer A, de Carvalho IA, Sadana R, Pot AM, Michel JP, et al. The World report on ageing and health: a policy framework for healthy ageing. Lancet 2016;387:2145-54.

2. Christensen K, Doblhammer G, Rau R, Vaupel JW. Ageing populations: the challenges ahead. Lancet 2009;374:1196208.

3. Marengoni A, Angleman S, Melis R, Mangialasche F, Karp A, Garmen A, et al. Aging with multimorbidity: a systematic review of the literature. Ageing Res Rev 2011;10:430-9.

4. Eckardt M, Brettschneider C, van den Bussche H, König HH; MultiCare Study Group. Analysis of health care costs in elderly patients with multiple chronic conditions using a finite mixture of generalized linear models. Health Econ 2017;26:
582-99.

5. Barzilai N, Cuervo AM, Austad S. Aging as a biological target for prevention and therapy. JAMA 2018;320:1321-2.

6. Feldman HA, Longcope C, Derby CA, Johannes CB, Araujo $\mathrm{AB}$, Coviello AD, et al. Age trends in the level of serum testosterone and other hormones in middle-aged men: longitudinal results from the Massachusetts male aging study. J Clin Endocrinol Metab 2002;87:589-98.

7. Camacho EM, Huhtaniemi IT, O’Neill TW, Finn JD, Pye SR, Lee DM, et al.; EMAS Group. Age-associated changes in hypothalamic-pituitary-testicular function in middle-aged and older men are modified by weight change and lifestyle factors: longitudinal results from the European Male Ageing Study. Eur J Endocrinol 2013;168:445-55.

8. Parker CR Jr. Dehydroepiandrosterone and dehydroepiandrosterone sulfate production in the human adrenal during development and aging. Steroids 1999;64:640-7.

9. Kaler LW, Neaves WB. Attrition of the human Leydig cell population with advancing age. Anat Rec 1978;192:513-8.

10. Walther A, Philipp M, Lozza N, Ehlert U. The rate of change in declining steroid hormones: a new parameter of healthy aging in men? Oncotarget 2016;7:60844-57.

11. Yeap BB, Manning L, Chubb SAP, Handelsman DJ, Almeida OP, Hankey GJ, et al. Progressive impairment of testicular endocrine function in ageing men: testosterone and dihydrotestosterone decrease, and luteinizing hormone increases, in men transitioning from the 8 th to 9 th decades of life. Clin Endocrinol (Oxf) 2018;88:88-95.

12. Hsu B, Cumming RG, Naganathan V, Blyth FM, Le Couteur DG, Hirani V, et al. Temporal changes in androgens and estrogens are associated with all-cause and cause-specific mortality in older men. J Clin Endocrinol Metab 2016;101:220110.

13. Zitzmann M. [Hormone replacement therapy in males]. Dtsch Med Wochenschr 2018;143:1405-16. German.

14. Basar MM, Aydin G, Mert HC, Keles I, Caglayan O, Orkun $S$, et al. Relationship between serum sex steroids and Aging Male Symptoms score and International Index of Erectile Function. Urology 2005;66:597-601.

15. Flood JF, Morley JE, Roberts E. Memory-enhancing effects in male mice of pregnenolone and steroids metabolically derived from it. Proc Natl Acad Sci U S A 1992;89:1567-71.

16. Herrington DM, Gordon GB, Achuff SC, Trejo JF, Weisman HF, Kwiterovich PO Jr, et al. Plasma dehydroepiandrosterone and dehydroepiandrosterone sulfate in patients undergoing diagnostic coronary angiography. J Am Coll Cardiol 1990;16: 862-70.

17. Roy TA, Blackman MR, Harman SM, Tobin JD, Schrager M, 
Metter EJ. Interrelationships of serum testosterone and free testosterone index with FFM and strength in aging men. Am J Physiol Endocrinol Metab 2002;283:E284-94.

18. Hyde Z, Flicker L, Almeida OP, Hankey GJ, McCaul KA, Chubb SA, et al. Low free testosterone predicts frailty in older men: the health in men study. J Clin Endocrinol Metab 2010;95:3165-72.

19. Ford AH, Yeap BB, Flicker L, Hankey GJ, Chubb SAP, Golledge J, et al. Sex hormones and incident dementia in older men: the health in men study. Psychoneuroendocrinology 2018;98:139-47.

20. Barrett-Connor E, Goodman-Gruen D, Patay B. Endogenous sex hormones and cognitive function in older men. J Clin Endocrinol Metab 1999;84:3681-5.

21. Ford AH, Yeap BB, Flicker L, Hankey GJ, Chubb SA, Handelsman DJ, et al. Prospective longitudinal study of testosterone and incident depression in older men: the health in men study. Psychoneuroendocrinology 2016;64:57-65.

22. Kische H, Pieper L, Venz J, Klotsche J, März W, KochGromus $\mathrm{U}$, et al. Longitudinal change instead of baseline testosterone predicts depressive symptoms. Psychoneuroendocrinology 2018;89:7-12.

23. Martin S, Atlantis E, Wilson D, Lange K, Haren MT, Taylor A, et al. Clinical and biopsychosocial determinants of sexual dysfunction in middle-aged and older Australian men. J Sex Med 2012;9:2093-103.

24. Shi MD, Chao JK, Ma MC, Hao LJ, Chao IC. Factors associated with sex hormones and erectile dysfunction in male Taiwanese participants with obesity. J Sex Med 2014;11:2309.

25. Walther A, Ehlert U. Steroid secretion and psychological well-being in men 40+. In: Rice TR, Sher L, editors. Neurobiology of men's mental health. New York: Nova Biomedical; 2015;287-322.

26. Fiacco S, Walther A, Ehlert U. Steroid secretion in healthy aging. Psychoneuroendocrinology 2018. doi: 10.1016/ j.psyneuen.2018.09.035 [Epub].

27. Tajar A, O’Connell MD, Mitnitski AB, O’Neill TW, Searle $\mathrm{SD}$, Huhtaniemi IT, et al. Frailty in relation to variations in hormone levels of the hypothalamic-pituitary-testicular axis in older men: results from the European male aging study. J Am Geriatr Soc 2011;59:814-21.

28. Baylis D, Bartlett DB, Syddall HE, Ntani G, Gale CR, Cooper $\mathrm{C}$, et al. Immune-endocrine biomarkers as predictors of frailty and mortality: a 10-year longitudinal study in community-dwelling older people. Age (Dordr) 2013;35:963-71.

29. Hildreth KL, Gozansky WS, Jankowski CM, Grigsby J, Wolfe P, Kohrt WM. Association of serum dehydroepiandrosterone sulfate and cognition in older adults: sex steroid, inflammatory, and metabolic mechanisms. Neuropsychology 2013;27: 356-63.

30. Fonda SJ, Bertrand R, O'Donnell A, Longcope C, McKinlay JB. Age, hormones, and cognitive functioning among middle-aged and elderly men: cross-sectional evidence from the Massachusetts male aging study. J Gerontol A Biol Sci Med Sci 2005;60:385-90.

31. Souza-Teodoro LH, de Oliveira C, Walters K, Carvalho LA. Higher serum dehydroepiandrosterone sulfate protects against the onset of depression in the elderly: findings from the English Longitudinal Study of Aging (ELSA). Psychoneuroendocrinology 2016;64:40-6.

32. Michikawa T, Nishiwaki Y, Nakano M, Iwasawa S, Yamada M, Asakura K, et al. Higher serum dehydroepiandrosterone sulfate levels are protectively associated with depressive symptoms in men, but not in women: a community-based cohort study of older Japanese. Am J Geriatr Psychiatry 2013;21: 1154-63.

33. Feldman HA, Goldstein I, Hatzichristou DG, Krane RJ, McKinlay JB. Impotence and its medical and psychosocial correlates: results of the Massachusetts Male Aging Study. J Urol 1994;151:54-61.

34. Elliott J, Kelly SE, Millar AC, Peterson J, Chen L, Johnston A, et al. Testosterone therapy in hypogonadal men: a systematic review and network meta-analysis. BMJ Open 2017;7: e015284.

35. Isidori AM, Giannetta E, Gianfrilli D, Greco EA, Bonifacio V, Aversa A, et al. Effects of testosterone on sexual function in men: results of a meta-analysis. Clin Endocrinol (Oxf) 2005; 63:381-94

36. Boloña ER, Uraga MV, Haddad RM, Tracz MJ, Sideras K, Kennedy CC, et al. Testosterone use in men with sexual dysfunction: a systematic review and meta-analysis of randomized placebo-controlled trials. Mayo Clin Proc 2007;82:20-8.

37. Walther A, Breidenstein J, Miller R. Association of testosterone treatment with alleviation of depressive symptoms in men: a systematic review and meta-analysis. JAMA Psychiatry 2019;76:31-40.

38. Corona G, Rastrelli G, Morgentaler A, Sforza A, Mannucci E, Maggi M. Meta-analysis of results of testosterone therapy on sexual function based on international index of erectile function scores. Eur Urol 2017;72:1000-11.

39. Corona G, Rastrelli G, Giagulli VA, Sila A, Sforza A, Forti G, et al. Dehydroepiandrosterone supplementation in elderly men: a meta-analysis study of placebo-controlled trials. J Clin Endocrinol Metab 2013;98:3615-26.

40. Corona G, Rastrelli G, Di Pasquale G, Sforza A, Mannucci 
E, Maggi M. Testosterone and cardiovascular risk: metaanalysis of interventional studies. J Sex Med 2018;15:820-38.

41. Grimley Evans J, Malouf R, Huppert F, van Niekerk JK. Dehydroepiandrosterone (DHEA) supplementation for cognitive function in healthy elderly people. Cochrane Database Syst Rev 2006;(4):CD006221.

42. Bhasin S, Brito JP, Cunningham GR, Hayes FJ, Hodis HN, Matsumoto AM, et al. Testosterone therapy in men with hypogonadism: an endocrine society clinical practice guideline. J Clin Endocrinol Metab 2018;103:1715-44.

43. Lippuner K, Johansson H, Kanis JA, Rizzoli R. Remaining lifetime and absolute 10-year probabilities of osteoporotic fracture in Swiss men and women. Osteoporos Int 2009;20: $1131-40$

44. Ensrud KE. Epidemiology of fracture risk with advancing age. J Gerontol A Biol Sci Med Sci 2013;68:1236-42.

45. Janssen I, Shepard DS, Katzmarzyk PT, Roubenoff R. The healthcare costs of sarcopenia in the United States. J Am Geriatr Soc 2004;52:80-5.

46. Snyder PJ, Peachey H, Berlin JA, Hannoush P, Haddad G, Dlewati A, et al. Effects of testosterone replacement in hypogonadal men. J Clin Endocrinol Metab 2000;85:2670-7.

47. Behre HM, Kliesch S, Leifke E, Link TM, Nieschlag E. Longterm effect of testosterone therapy on bone mineral density in hypogonadal men. J Clin Endocrinol Metab 1997;82:238690.

48. Amory JK, Watts NB, Easley KA, Sutton PR, Anawalt BD, Matsumoto AM, et al. Exogenous testosterone or testosterone with finasteride increases bone mineral density in older men with low serum testosterone. J Clin Endocrinol Metab 2004;89:503-10.

49. Kenny AM, Prestwood KM, Gruman CA, Marcello KM, Raisz LG. Effects of transdermal testosterone on bone and muscle in older men with low bioavailable testosterone levels. J Gerontol A Biol Sci Med Sci 2001;56:M266-72.

50. Snyder PJ, Peachey H, Hannoush P, Berlin JA, Loh L, Holmes $\mathrm{JH}$, et al. Effect of testosterone treatment on bone mineral density in men over 65 years of age. J Clin Endocrinol Metab 1999;84:1966-72.

51. Emmelot-Vonk MH, Verhaar HJ, Nakhai Pour HR, Aleman A, Lock TM, Bosch JL, et al. Effect of testosterone supplementation on functional mobility, cognition, and other parameters in older men: a randomized controlled trial. JAMA 2008;299:39-52.

52. Snyder PJ, Kopperdahl DL, Stephens-Shields AJ, Ellenberg SS, Cauley JA, Ensrud KE, et al. Effect of testosterone treatment on volumetric bone density and strength in older men with low testosterone: a controlled clinical trial. JAMA In- tern Med 2017;177:471-9.

53. Corona G, Giagulli VA, Maseroli E, Vignozzi L, Aversa A, Zitzmann M, et al. Therapy of endocrine disease: testosterone supplementation and body composition: results from a meta-analysis study. Eur J Endocrinol 2016;174:R99-116.

54. Matthews FE, Arthur A, Barnes LE, Bond J, Jagger C, Robinson L, et al. A two-decade comparison of prevalence of dementia in individuals aged 65 years and older from three geographical areas of England: results of the cognitive function and ageing study I and II. Lancet 2013;382:1405-12.

55. Cherrier MM, Matsumoto AM, Amory JK, Asthana S, Bremner W, Peskind ER, et al. Testosterone improves spatial memory in men with Alzheimer disease and mild cognitive impairment. Neurology 2005;64:2063-8.

56. Lu PH, Masterman DA, Mulnard R, Cotman C, Miller B, Yaffe $\mathrm{K}$, et al. Effects of testosterone on cognition and mood in male patients with mild Alzheimer disease and healthy elderly men. Arch Neurol 2006;63:177-85.

57. Cherrier MM, Anderson K, Shofer J, Millard S, Matsumoto AM. Testosterone treatment of men with mild cognitive impairment and low testosterone levels. Am J Alzheimers Dis Other Demen 2015;30:421-30.

58. Cherrier MM, Asthana S, Plymate S, Baker L, Matsumoto $\mathrm{AM}$, Peskind E, et al. Testosterone supplementation improves spatial and verbal memory in healthy older men. Neurology 2001;57:80-8.

59. Vaughan C, Goldstein FC, Tenover JL. Exogenous testosterone alone or with finasteride does not improve measurements of cognition in healthy older men with low serum testosterone. J Androl 2007;28:875-82.

60. Haren MT, Wittert GA, Chapman IM, Coates P, Morley JE. Effect of oral testosterone undecanoate on visuospatial cognition, mood and quality of life in elderly men with lownormal gonadal status. Maturitas 2005;50:124-33.

61. Kenny AM, Fabregas G, Song C, Biskup B, Bellantonio S. Effects of testosterone on behavior, depression, and cognitive function in older men with mild cognitive loss. J Gerontol A Biol Sci Med Sci 2004;59:75-8.

62. Resnick SM, Matsumoto AM, Stephens-Shields AJ, Ellenberg SS, Gill TM, Shumaker SA, et al. Testosterone treatment and cognitive function in older men with low testosterone and age-associated memory impairment. JAMA 2017;317:71727.

63. World Health Organization. Depression and other common mental disorders: global health estimates. Geneva: World Health Organization; 2017.

64. Rabkin JG, Wagner GJ, Rabkin R. A double-blind, placebocontrolled trial of testosterone therapy for HIV-positive men 
with hypogonadal symptoms. Arch Gen Psychiatry 2000;57: 141-7; discussion 155-6.

65. Pope HG Jr, Cohane GH, Kanayama G, Siegel AJ, Hudson JI. Testosterone gel supplementation for men with refractory depression: a randomized, placebo-controlled trial. Am J Psychiatry 2003;160:105-11.

66. Seidman SN, Orr G, Raviv G, Levi R, Roose SP, Kravitz E, et al. Effects of testosterone replacement in middle-aged men with dysthymia: a randomized, placebo-controlled clinical trial. J Clin Psychopharmacol 2009;29:216-21.

67. Rabkin JG, Wagner GJ, McElhiney MC, Rabkin R, Lin SH. Testosterone versus fluoxetine for depression and fatigue in HIV/AIDS: a placebo-controlled trial. J Clin Psychopharmacol 2004;24:379-85.

68. Seidman SN, Miyazaki M, Roose SP. Intramuscular testosterone supplementation to selective serotonin reuptake inhibitor in treatment-resistant depressed men: randomized placebo-controlled clinical trial. J Clin Psychopharmacol 2005;25:584-8.

69. Cavallini G, Caracciolo S, Vitali G, Modenini F, Biagiotti G. Carnitine versus androgen administration in the treatment of sexual dysfunction, depressed mood, and fatigue associated with male aging. Urology 2004;63:641-6.

70. Snyder PJ, Bhasin S, Cunningham GR, Matsumoto AM, Stephens-Shields AJ, Cauley JA, et al. Effects of testosterone treatment in older men. N Engl J Med 2016;374:611-24.

71. Svartberg J, Agledahl I, Figenschau Y, Sildnes T, Waterloo $\mathrm{K}$, Jorde R. Testosterone treatment in elderly men with subnormal testosterone levels improves body composition and BMD in the hip. Int J Impot Res 2008;20:378-87.

72. National Collaborating Centre for Mental Health (UK). Depression: the treatment and management of depression in adults (updated edition). Leicester: British Psychological Society; 2010.

73. Saigal CS, Wessells H, Pace J, Schonlau M, Wilt TJ. Predictors and prevalence of erectile dysfunction in a racially diverse population. Arch Intern Med 2006;166:207-12.

74. Morales A, Black A, Emerson L, Barkin J, Kuzmarov I, Day A. Androgens and sexual function: a placebo-controlled, randomized, double-blind study of testosterone vs. dehydroepiandrosterone in men with sexual dysfunction and androgen deficiency. Aging Male 2009;12:104-12.

75. Gianatti EJ, Dupuis P, Hoermann R, Zajac JD, Grossmann M. Effect of testosterone treatment on constitutional and sexual symptoms in men with type 2 diabetes in a randomized, placebo-controlled clinical trial. J Clin Endocrinol Metab 2014; 99:3821-8.

76. Hackett G, Cole N, Bhartia M, Kennedy D, Raju J, Wilkinson
P. Testosterone replacement therapy with long-acting testosterone undecanoate improves sexual function and qualityof-life parameters vs. placebo in a population of men with type 2 diabetes. J Sex Med 2013;10:1612-27.

77. Giltay EJ, Tishova YA, Mskhalaya GJ, Gooren LJ, Saad F, Kalinchenko SY. Effects of testosterone supplementation on depressive symptoms and sexual dysfunction in hypogonadal men with the metabolic syndrome. J Sex Med 2010;7:257282.

78. Brock G, Heiselman D, Maggi M, Kim SW, Rodríguez Vallejo JM, Behre HM, et al. Effect of testosterone solution $2 \%$ on testosterone concentration, sex drive and energy in hypogonadal men: results of a placebo controlled study. J Urol 2016; 195:699-705.

79. Cunningham GR, Stephens-Shields AJ, Rosen RC, Wang C, Bhasin S, Matsumoto AM, et al. Testosterone treatment and sexual function in older men with low testosterone levels. J Clin Endocrinol Metab 2016;101:3096-104.

80. Corona G, Isidori AM, Buvat J, Aversa A, Rastrelli G, Hackett $G$, et al. Testosterone supplementation and sexual function: a meta-analysis study. J Sex Med 2014;11:1577-92.

81. Baulieu EE, Thomas G, Legrain S, Lahlou N, Roger M, Debuire B, et al. Dehydroepiandrosterone (DHEA), DHEA sulfate, and aging: contribution of the DHEAge Study to a sociobiomedical issue. Proc Natl Acad Sci U S A 2000;97:427984.

82. Nair KS, Rizza RA, O’Brien P, Dhatariya K, Short KR, Nehra A, et al. DHEA in elderly women and DHEA or testosterone in elderly men. N Engl J Med 2006;355:1647-59.

83. Weiss EP, Villareal DT, Fontana L, Han DH, Holloszy JO. Dehydroepiandrosterone (DHEA) replacement decreases insulin resistance and lowers inflammatory cytokines in aging humans. Aging (Albany NY) 2011;3:533-42.

84. Morales AJ, Haubrich RH, Hwang JY, Asakura H, Yen SS. The effect of six months treatment with a $100 \mathrm{mg}$ daily dose of dehydroepiandrosterone (DHEA) on circulating sex steroids, body composition and muscle strength in ageadvanced men and women. Clin Endocrinol (Oxf) 1998;49: 421-32.

85. Wolf OT, Neumann O, Hellhammer DH, Geiben AC, Strasburger CJ, Dressendörfer RA, et al. Effects of a two-week physiological dehydroepiandrosterone substitution on cognitive performance and well-being in healthy elderly women and men. J Clin Endocrinol Metab 1997;82:2363-7.

86. Wolf OT, Kudielka BM, Hellhammer DH, Hellhammer J, Kirschbaum C. Opposing effects of DHEA replacement in elderly subjects on declarative memory and attention after exposure to a laboratory stressor. Psychoneuroendocrinol- 
ogy 1998;23:617-29.

87. Huppert FA, Van Niekerk JK, Herbert J. Dehydroepiandrosterone (DHEA) supplementation for cognition and wellbeing. Cochrane Database Syst Rev 2000;(2):CD000304.

88. Kritz-Silverstein D, von Mühlen D, Laughlin GA, Bettencourt R. Effects of dehydroepiandrosterone supplementation on cognitive function and quality of life: the DHEA and Well-Ness (DAWN) Trial. J Am Geriatr Soc 2008;56:1292-8.

89. Alhaj HA, Massey AE, McAllister-Williams RH. Effects of DHEA administration on episodic memory, cortisol and mood in healthy young men: a double-blind, placebo-controlled study. Psychopharmacology (Berl) 2006;188:541-51.

90. Rabkin JG, McElhiney MC, Rabkin R, McGrath PJ, Ferrando SJ. Placebo-controlled trial of dehydroepiandrosterone (DHEA) for treatment of nonmajor depression in patients with HIV/AIDS. Am J Psychiatry 2006;163:59-66.

91. Schmidt PJ, Daly RC, Bloch M, Smith MJ, Danaceau MA, St Clair LS, et al. Dehydroepiandrosterone monotherapy in midlife-onset major and minor depression. Arch Gen Psychiatry 2005;62:154-62.

92. Wolkowitz OM, Reus VI, Keebler A, Nelson N, Friedland M, Brizendine L, et al. Double-blind treatment of major depression with dehydroepiandrosterone. Am J Psychiatry 1999; 156:646-9.

93. Peixoto C, Grande AJ, Mallmann MB, Nardi AE, Cardoso A, Veras AB. Dehydroepiandrosterone (DHEA) for depression: a systematic review and meta-analysis. CNS Neurol Disord Drug Targets 2018;17:706-11.

94. Reiter WJ, Schatzl G, Märk I, Zeiner A, Pycha A, Marberger $M$. Dehydroepiandrosterone in the treatment of erectile dysfunction in patients with different organic etiologies. Urol Res 2001;29:278-81.

95. Tekdogan U, Tuncel A, Tuglu D, Basar MM, Atan A. Effect of sildenafil citrate treatment on serum dehydroepiandros- terone sulfate levels in patients with erectile dysfunction. Urology 2006;68:626-30.

96. Bloch M, Meiboom H, Zaig I, Schreiber S, Abramov L. The use of dehydroepiandrosterone in the treatment of hypoactive sexual desire disorder: a report of gender differences. Eur Neuropsychopharmacol 2013;23:910-8.

97. Walther A, Mahler F, Debelak R, Ehlert U. Psychobiological protective factors modifying the association between age and sexual health in men: findings from the men's health $40+$ study. Am J Mens Health 2017;11:737-47.

98. Brown GA, Vukovich MD, Sharp RL, Reifenrath TA, Parsons KA, King DS. Effect of oral DHEA on serum testosterone and adaptations to resistance training in young men. J Appl Physiol (1985) 1999;87:2274-83.

99. Vigen R, O’Donnell CI, Barón AE, Grunwald GK, Maddox TM, Bradley SM, et al. Association of testosterone therapy with mortality, myocardial infarction, and stroke in men with low testosterone levels. JAMA 2013;310:1829-36.

100. Finkle WD, Greenland S, Ridgeway GK, Adams JL, Frasco $\mathrm{MA}$, Cook MB, et al. Increased risk of non-fatal myocardial infarction following testosterone therapy prescription in men. PLoS One 2014;9:E85805.

101. Morgentaler A, Zitzmann M, Traish AM, Fox AW, Jones TH, Maggi M, et al. Fundamental concepts regarding testosterone deficiency and treatment: international expert consensus resolutions. Mayo Clin Proc 2016;91:881-96.

102. Food \& Drug Administration. FDA Drug Safety Communication: FDA cautions about using testosterone products for low testosterone due to aging; requires labeling change to inform of possible increased risk of heart attack and stroke with use. Silver Spring: Food \& Drug Administration; 2015

103. European Medicines Agency. No consistent evidence of an increased risk of heart problems with testosterone medicines. Amsterdam: European Medicines Agency; 2014. 